\title{
A Raman Spectroscopic and Computational Study of New Aromatic Pyrimidine-Based Halogen Bond Acceptors
}

\author{
April E. S. Hardin ${ }^{1}$, Thomas L. Ellington ${ }^{1}{ }^{\mathbb{D}}$, Suong T. Nguyen ${ }^{1}$, Arnold L. Rheingold ${ }^{2}{ }^{\circledR}$, \\ Gregory S. Tschumper ${ }^{1}\left(\mathbb{D}\right.$, Davita L. Watkins ${ }^{1}\left(\mathbb{D}\right.$ and Nathan I. Hammer ${ }^{1, *(D)}$ \\ 1 Molecular Spectroscopy Laboratories, Department of Chemistry \& Biochemistry, University of Mississippi, \\ University, MS 38677, USA; aesteen@go.olemiss.edu (A.E.S.H.); thomas_ellington@baylor.edu (T.L.E.); \\ suongnguyen891994@gmail.com (S.T.N.); tschumpr@olemiss.edu (G.S.T.); dwatkins@olemiss.edu (D.L.W.) \\ 2 Department of Chemistry, University of California, San Diego, La Jolla, CA 92093-0358, USA; \\ arheingold@ucsd.edu \\ * Correspondence: nhammer@olemiss.edu; Tel.: +1-662-915-3989
}

Received: 7 September 2019; Accepted: 27 September 2019; Published: 2 October 2019

\begin{abstract}
Two new aromatic pyrimidine-based derivatives designed specifically for halogen bond directed self-assembly are investigated through a combination of high-resolution Raman spectroscopy, X-ray crystallography, and computational quantum chemistry. The vibrational frequencies of these new molecular building blocks, pyrimidine capped with furan (PrmF) and thiophene (PrmT), are compared to those previously assigned for pyrimidine (Prm). The modifications affect only a select few of the normal modes of Prm, most noticeably its signature ring breathing mode, $v_{1}$. Structural analyses afforded by $\mathrm{X}$-ray crystallography, and computed interaction energies from density functional theory computations indicate that, although weak hydrogen bonding $(\mathrm{C}-\mathrm{H} \cdots \mathrm{O}$ or $\mathrm{C}-\mathrm{H} \cdots \mathrm{N}$ interactions $)$ is present in these pyrimidine-based solid-state co-crystals, halogen bonding and $\pi$-stacking interactions play more dominant roles in driving their molecular-assembly.
\end{abstract}

Keywords: halogen bonding; sigma-hole interactions; molecular recognition; self-assembly; supramolecular structures; crystal engineering; computational chemistry; supramolecular chemistry; vibrational spectroscopy; noncovalent interactions

\section{Introduction}

It is well-accepted in the field of crystal engineering that noncovalent interactions play dominant roles in directing self-assembly [1-6]. In addition to the commonly discussed hydrogen bonding interaction, $\pi-\pi$ and halogen bond interactions have also been shown to play important, and sometimes even more dominant roles, in determining the resulting crystal structures and bulk properties [7-19]. A halogen bond is a noncovalent interaction involving the net attraction between an electrophilic region of a halogen atom (e.g., bromide or iodide; $\mathrm{C}-\mathrm{Br}$ or $\mathrm{C}-\mathrm{I}$ ) on one molecule, and the nucleophilic region of another or the same molecule [20]. Electron withdrawing atoms such as fluorine or similar functional groups on the halogen bond donor have been shown to significantly enhance this $\sigma$-hole interaction, to the point of even energetically competing with hydrogen bonding interactions [21]. Halogen bond acceptors typically incorporate a heterocyclic nitrogen atom, with the lone pairs playing a central role in the noncovalent interaction. Pyridine- and pyrimidine-based derivatives therefore make ideal halogen bond accepting building blocks, and a number of architectures incorporating various combinations of donors and acceptors have been introduced in recent years [17-19].

Noteworthy are the applications of halogen bonding interactions in materials research and engineering [22-24]. We, like others, have shown the impact of halogen bonding in optoelectronic 
and semiconducting materials [25-29]. Because of its synthetic accessibility, one of the most common building blocks used in the development of organic semiconducting materials is the sulfur-containing heterocycle thiophene [30]. Oligofurans have also emerged as promising building blocks for self-assembled organic semiconducting materials [30-39]. The presence of the oxygen atom in place of a sulfur atom in the five-membered aromatic heterocyclic rings gives rise to electron-rich conjugated systems exhibiting a tighter solid-state packing and even greater rigidity when compared to those of thiophene analogues $[38,40,41]$. The combination of the nitrogen atoms in the heterocyclic pyrimidine rings with the semiconducting and self-assembly properties of thiophene and furan groups thus offer the potential of powerful new building blocks for the halogen bond directed supramolecular assembly of semiconducting materials.

Our research groups have studied the Raman vibrational spectra and the effects that noncovalent interactions and charge delocalization have on the normal modes of pyrimidine for over a decade [21, 42-49]. We have quantified hydrogen bonding interactions involving pyrimidine with water, methanol, ethylene glycol, and other species [42,43,45]; argyrophilic interactions with silver island films [48]; solid-state interactions between pyrimidine molecules [44]; and halogen bonding interactions with a variety of donors [21]. We have also demonstrated that the Raman spectra of pyrimidine in the solid-state is only weakly perturbed from that of the liquid, and that computational chemistry could be utilized to accurately assign normal modes and assess the effects of weak interactions in the solid-state [44]. Interestingly, weak $\mathrm{C}-\mathrm{H} \cdots \mathrm{N}$ interactions were found to dominate the solid-state structure of pure pyrimidine and the normal modes most affected involved the displacement of hydrogen atoms. For example, the hydrogen bending mode, $v_{3}$, exhibits a shift of $+14 \mathrm{~cm}^{-1}$ when transitioning to the solid state.

Here, we explore the effects of the addition of either a furan or thiophene group on the vibrational frequencies of the halogen bond acceptor pyrimidine, and we assign normal modes in these molecules for the first time. The two molecules of interest, 5-(furan-2-yl)pyrimidine (denoted PrmF) and 5-(thiophen-2-yl)pyrimidine (denoted PrmT), are shown in Figure 1. We also construct co-crystals with a previously introduced halogen bond donor, and compare the resulting pairwise interactions to those in other previously described systems $[18,19]$.
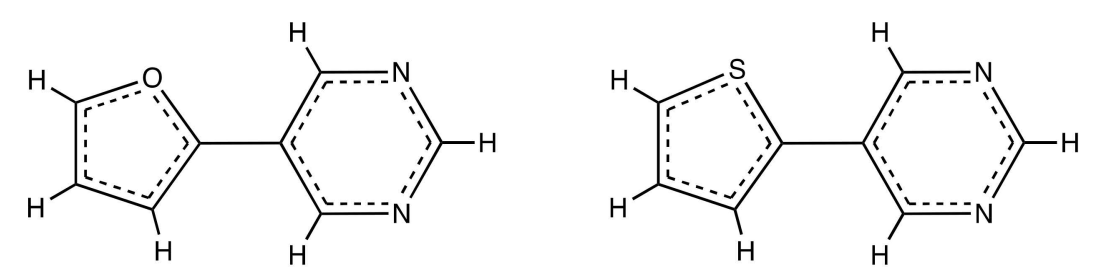

Figure 1. Furan (PrmF; left) and thiophene (PrmT; right) derivatives of pyrimidine considered here.

\section{Results}

\subsection{Experimental Results}

Figure 2 compares the experimental solid-state Raman spectra of pyrimidine (Prm) to that of its furan (PrmF) and thiophene (PrmT) analogues in the fingerprint region $\left(\leq 1700 \mathrm{~cm}^{-1}\right)$. We previously characterized the effects of noncovalent interactions on ten normal modes of pyrimidine in the region [42-45], and Figure 3 compares the Raman spectra in regions of these modes in greater detail. The $\mathrm{C}-\mathrm{H}$ stretching region is not considered here because of the congestion of the modes. It is evident from Figures 2 and 3 that, when compared to Prm, the vibrational spectra of PrmF and PrmT exhibit additional peaks because of the motions involving furan and thiophene, and also the peaks originating from the frequencies that have shifted upon the addition of the furan and thiophene groups. The features in the regions of interest in the derivatives also suffer from low signal to noise in some cases. 


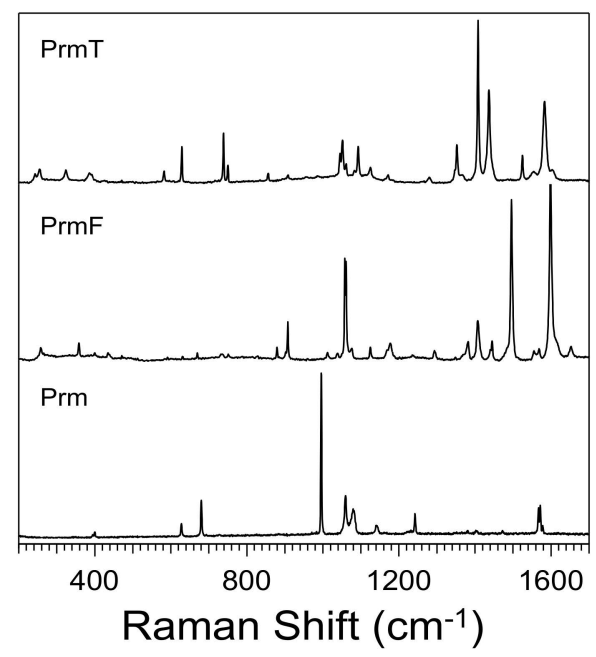

Figure 2. Experimental solid-state Raman spectra of pyrimidine (Prm) compared to that of its furan (PrmF) and thiophene (PrmT) analogues in the fingerprint region.

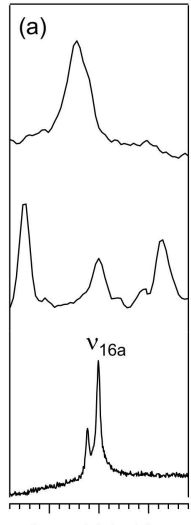

375400425

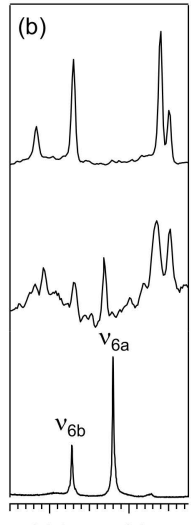

600700
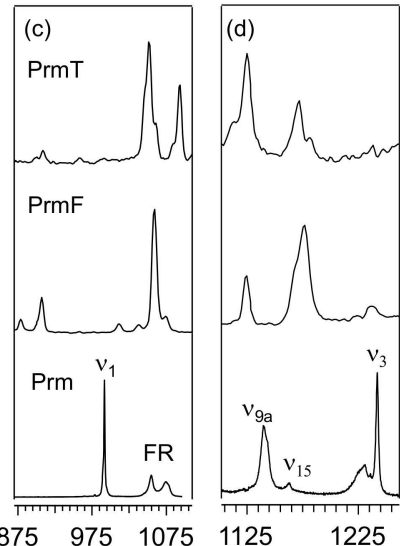

1125

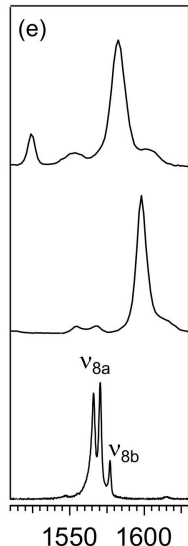

15501600

\section{Raman Shift $\left(\mathrm{cm}^{-1}\right)$}

Figure 3. Experimental solid-state Raman spectra of pyrimidine (Prm) compared to that of its furan (PrmF) and thiophene (PrmT) analogues in the regions of ten of Prm's normal modes. Modes previously assigned for Prm and Prm's Fermi resonance (FR) are indicated.

An overarching goal of our work is to develop new building blocks for self-assembly that have designer properties that can be systematically tailored. Co-crystallization provides simple yet direct means towards elucidating the effects of the noncovalent interactions on these building blocks. Co-crystallization of the halogen bond donor 1-(iodoethynyl)-3,5-dinitrobenzene, $\left(\mathrm{NO}_{2}\right)_{2} \mathrm{BAI}$, with PrmF, yields a triclinic structure with a $\mathrm{P} \overline{1}$ space group, with key interactions highlighted in the top panel of Figure 4, and the crystallographic data detailed in Table 1. There are two unique halogen bond interactions between the donor and acceptor molecules in co-crystal $\left(\mathrm{NO}_{2}\right)_{2} \mathrm{BAI}-\mathrm{PrmF}$, as follows: one exhibiting a N...I distance of $2.79 \AA$ i with a N $\cdots$ I-C angle of $177.3^{\circ}$, and a second possessing a $177.1^{\circ}$ angle with a separation of $2.83 \AA$. The interaction corresponds to a $32.0 \%-33.0 \%$ decrease in the total van der Waals radii of the nitrogen and iodine [18,50]. The 1:1 solid-state co-crystals formed between $\left(\mathrm{NO}_{2}\right)_{2} \mathrm{BAI}$ and PrmT yields crystallization in the monoclinic space group $\mathrm{P} 2{ }_{1} / \mathrm{n}$. A crystallographic disorder at the thiophene moiety on PrmT is evident by the presence of two distinct pairwise contacts. The averaged monotopic interactions between a nitrogen on $\operatorname{PrmT}$ and iodine are characterized by

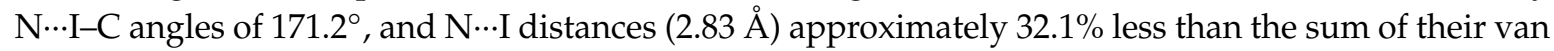
der Waals radii (bottom panel of Figure 4). Like $\left(\mathrm{NO}_{2}\right)_{2} \mathrm{BAI}-\mathrm{PrmF}$, co-crystal $\left(\mathrm{NO}_{2}\right)_{2} \mathrm{BAI}$-PrmT consists of weaker secondary hydrogen bond interactions $\left(\mathrm{NO}_{2} \cdots \mathrm{HPrmT}\right)$. However, donor-acceptor $\pi$-stacking 
arrangements are larger, exhibiting distances of $4.09 \AA\left(\mathrm{E}_{\mathrm{int}}=-6.8 \mathrm{kcal} \mathrm{mol}^{-1}\right)$ because of the increased size of the sulfur atom relative to the oxygen. In addition, dimers produced via halogen bonding pack parallel to each other into two-dimensional arrays along the c-axis affording weaker $\pi-\pi$ interactions between like molecules (i.e., $\left.\left(\mathrm{NO}_{2}\right)_{2} \mathrm{BAI} \cdots\left(\mathrm{NO}_{2}\right)_{2} \mathrm{BAI}\right)$. Figure 5 shows the experimental Raman spectra of $\left(\mathrm{NO}_{2}\right)_{2} \mathrm{BAI}$, and co-crystals formed with either PrmF or PrmT. Figure 6 highlights the Raman spectra of the co-crystals in three spectral regions in greater detail. Figure $\mathrm{S} 6$ includes a comparison of the experimental Raman spectra of Prm, PrmF, PrmT, $\left(\mathrm{NO}_{2}\right)_{2} \mathrm{BAI}-\mathrm{PrmF},\left(\mathrm{NO}_{2}\right)_{2} \mathrm{BAI}-\mathrm{PrmT}$, and $\left(\mathrm{NO}_{2}\right)_{2} \mathrm{BAI}$.
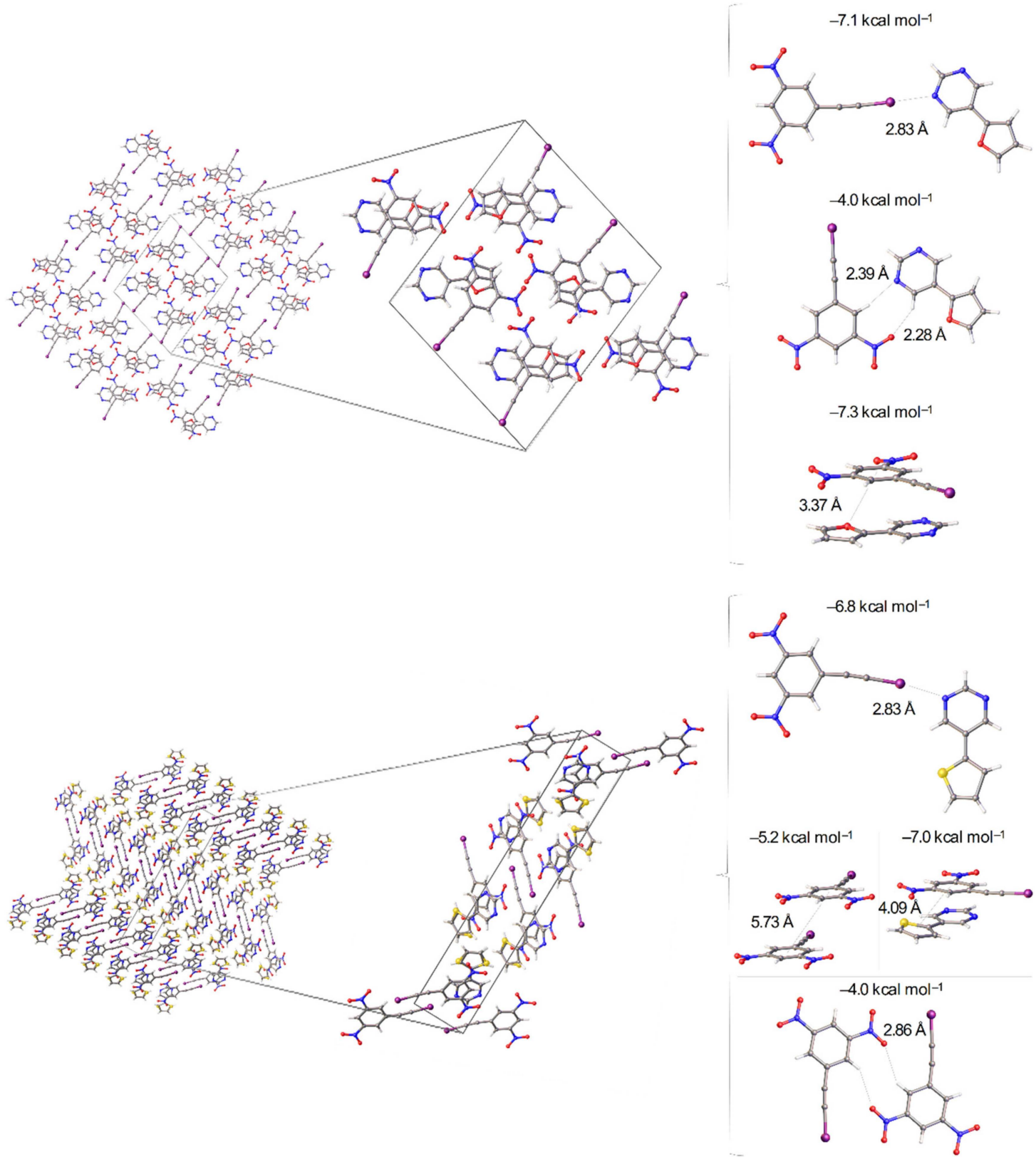

Figure 4. Halogen bond and weak hydrogen bonding interactions present in co-crystals formed from $\left(\mathrm{NO}_{2}\right)_{2} \mathrm{BAI}$ and PrmF (top) and PrmT (bottom). Details of the nearest neighbor interactions are included on the panel on the right. 
Table 1. Crystallographic data for $\left(\mathrm{NO}_{2}\right)_{2} \mathrm{BAI}-\mathrm{PrmF}$ and $\left(\mathrm{NO}_{2}\right)_{2} \mathrm{BAI}-\mathrm{PrmT}$ complexes.

\begin{tabular}{ccc}
\hline Co-Crystal & $\mathbf{( N O}_{\mathbf{2}} \mathbf{~}_{\mathbf{2}} \mathbf{B A I - P r m F}$ & $\mathbf{( N O}_{\mathbf{2}} \mathbf{~}_{\mathbf{2}} \mathbf{B A I - P r m \mathbf { T } ^ { \boldsymbol { a } }}$ \\
\hline$M\left(\mathrm{~g} \mathrm{\textrm {mol } ^ { - 1 } )}\right.$ & 464.2 & 960.5 \\
Temperature $(\mathrm{K})$ & 100.0 & 100.0 \\
Space Group & $\mathrm{P} \overline{1}$ & $\mathrm{P} 21 / \mathrm{n}$ \\
$a(\AA)$ & $6.9398(10)$ & $9.2195(6)$ \\
$b(\AA)$ & $16.126(2)$ & $5.7344(4)$ \\
$c(\AA)$ & $18.517(3)$ & $32.1204(16)$ \\
$\alpha\left(^{\circ}\right)$ & 79.34 & 90.00 \\
$\beta\left(^{\circ}\right)$ & 80.01 & 93.21 \\
$\gamma\left({ }^{\circ}\right)$ & 89.24 & 90.00 \\
$V\left(\AA^{3}\right)$ & 2005.2 & 1695.5 \\
$Z$ & 4 & 2 \\
$R$ Factor $(\%)$ & 4.84 & 4.38 \\
\hline
\end{tabular}

${ }^{a}$ Molecular formula and mass account for disorder at the thiophene moiety.

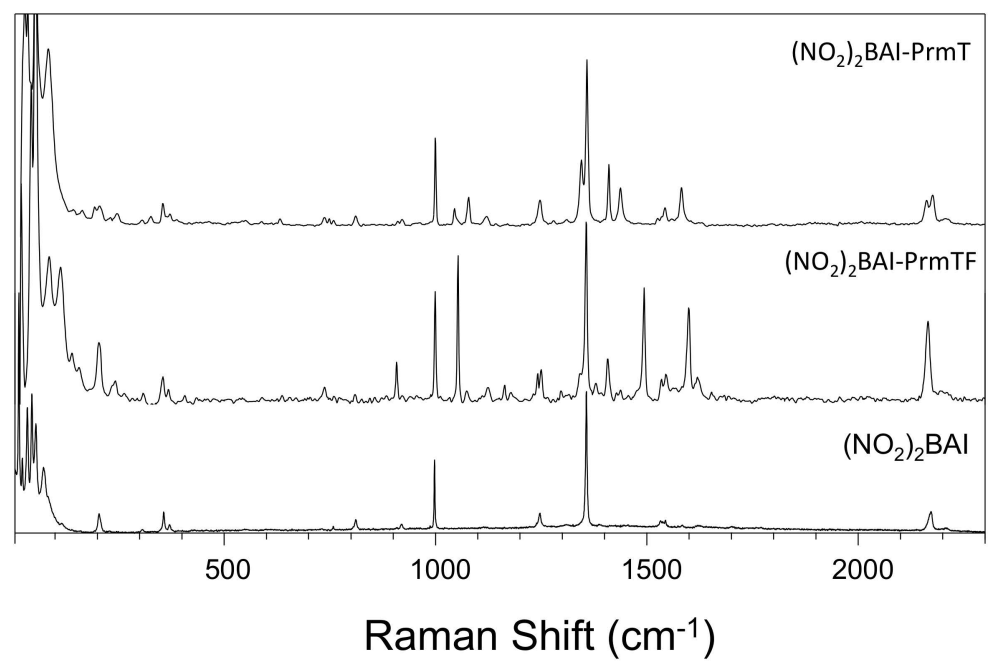

Figure 5. Experimental Raman spectra of $\left(\mathrm{NO}_{2}\right)_{2} \mathrm{BAI}$ (bottom), and co-crystals formed from $\left(\mathrm{NO}_{2}\right)_{2} \mathrm{BAI}$ with either PrmF (middle) or PrmT (top).
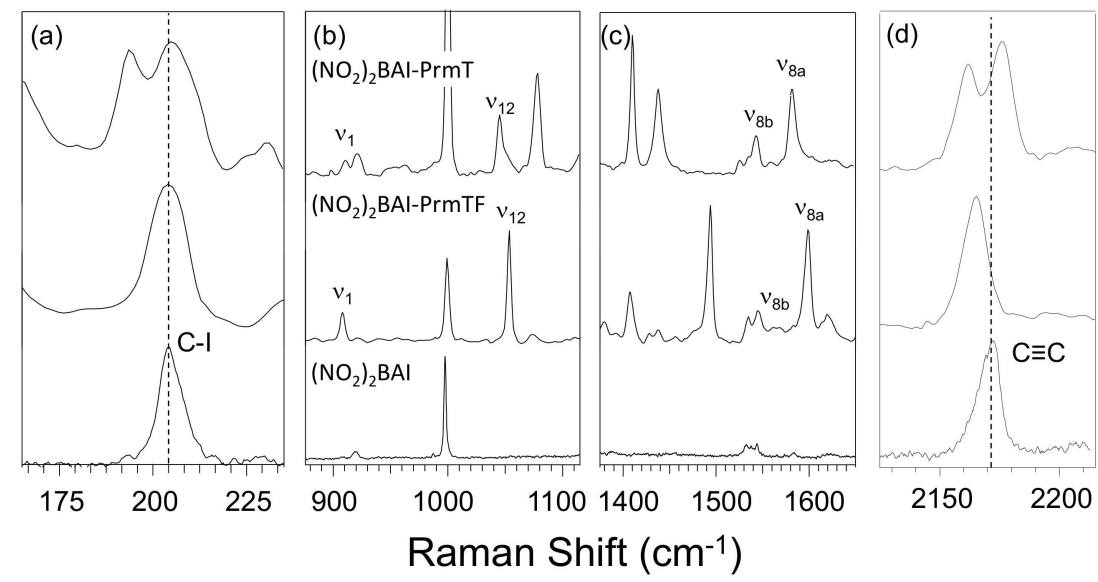

Figure 6. Experimental Raman spectra of $\left(\mathrm{NO}_{2}\right)_{2} \mathrm{BAI}$ (bottom), and the co-crystals formed from $\left(\mathrm{NO}_{2}\right)_{2} \mathrm{BAI}$ with either PrmF (middle) or PrmT (top) in different spectral regions. 


\subsection{Computational Results}

To aid in the assignment of normal modes and in the elucidation of the effects of the addition of the furan and thiophene groups on pyrimidine's nitrogen atoms, the structures and Raman spectra of PrmF and PrmT were predicted using computational chemistry. Figure 7 shows the optimized molecular structures of PrmF and PrmT at the M06-2X/aVTZ level of theory. Interestingly, whereas the minimum energy structure of PrmF is completely planar ( $C_{s}$ symmetry), the thiophene moiety in PrmT is twisted out of plane by $28^{\circ}$. Although the planar analogue of PrmT is only $0.35 \mathrm{kcal} / \mathrm{mol} \mathrm{higher} \mathrm{in}$ energy than the nonplanar minimum, it is a transition state $\left(n_{i}=1\right)$ on the M06-2X/aVTZ potential energy surface. This qualitative structural difference is likely due to sulfur having an atomic radius $22 \%$ larger than that of oxygen [50], which, in turn, results in more steric interactions between the protons of the thiophene moiety [51]. A comparison of the simulated Raman spectra (after scaling the harmonic frequencies by 0.956 to partially account for anharmonicity) [52] of isolated Prm molecules compared to those of isolated PrmF and PrmT molecules are shown in Figure 8. Individual comparisons between theory and experiment for Prm, PrmF and PrmT are shown in Figure S5, Figure 9, and Figure 10, respectively. The spectral features in Figures 9 and 10 that are readily assigned to furan are labeled with the letter $\mathrm{F}$, and those from thiophene with $\mathrm{T}$. Although the simulated vibrational structure differs significantly for each molecule, the simulated spectra in each region of interest strongly resembles the solid-state experimental spectra in each individual case, suggesting that the computational procedure employed in this work will assist in the assignment of the solid-state normal modes of the pyrimidine moiety in PrmF and PrmT.
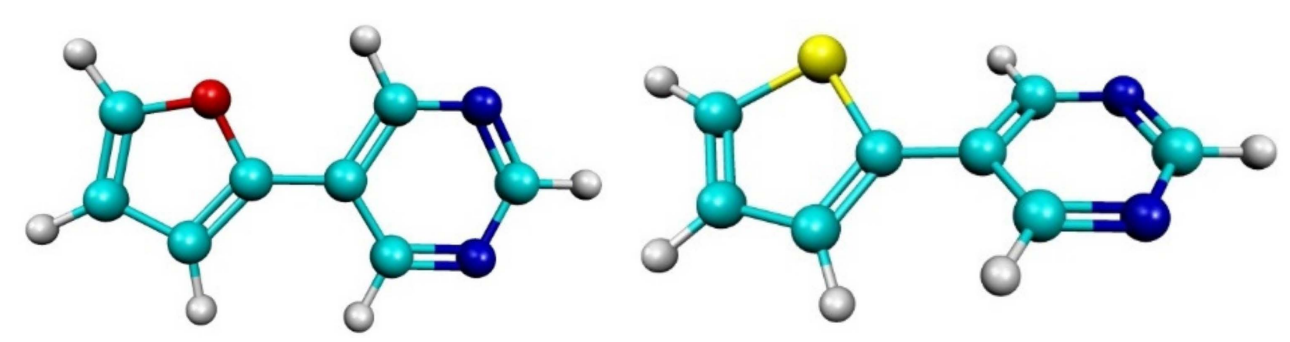

Figure 7. Optimized molecular structures of PrmF (left) and PrmT (right).

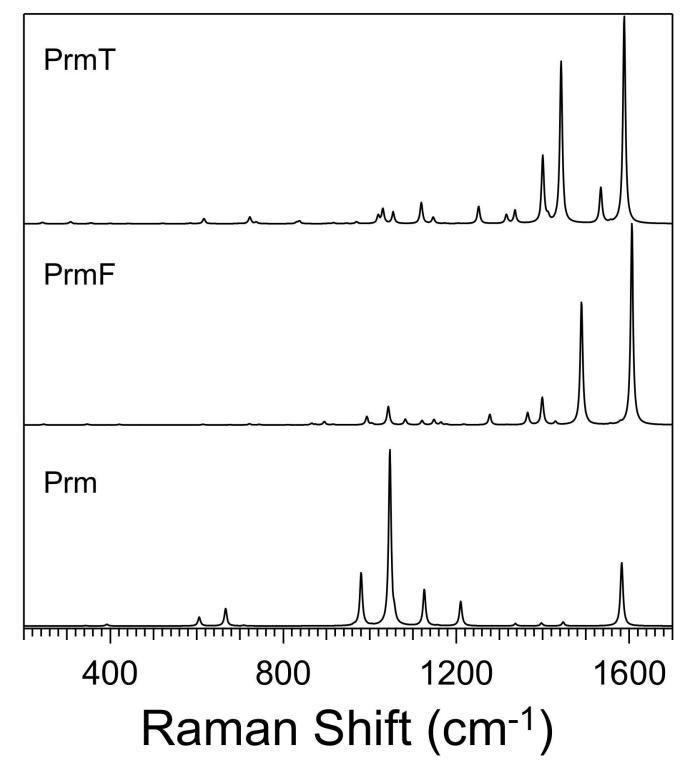

Figure 8. Simulated Raman spectra of pyrimidine (Prm) compared to that of PrmF and PrmT. 


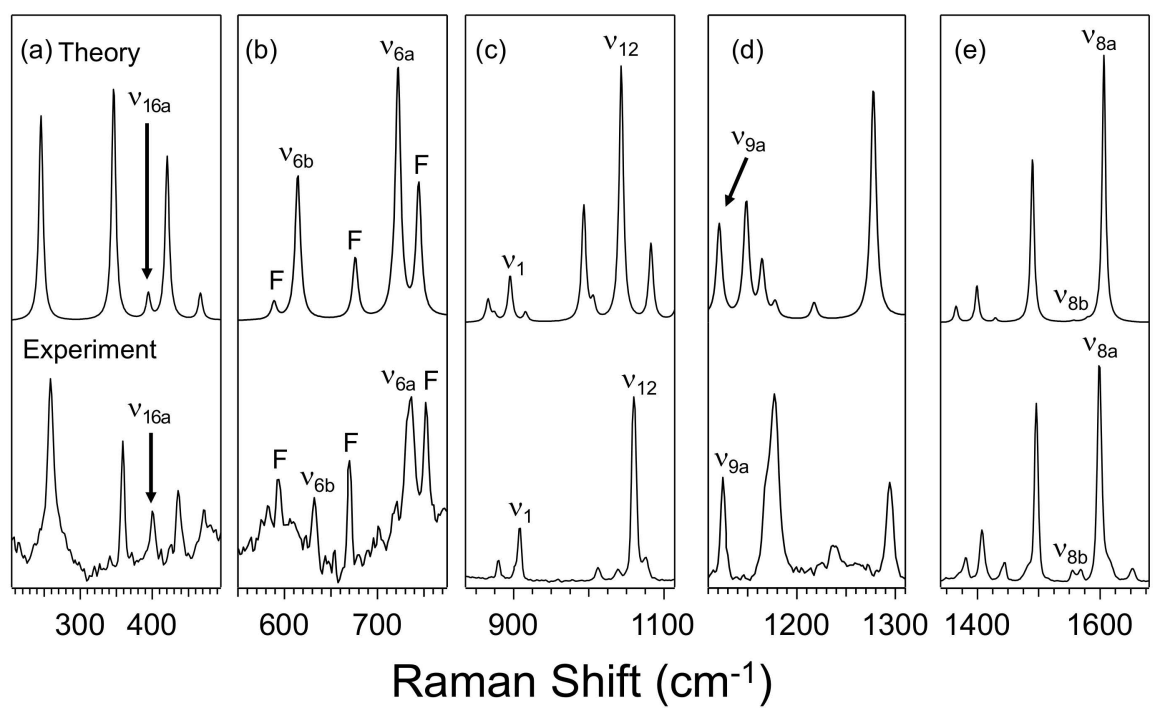

Figure 9. Experimental Raman spectra of PrmF (bottom) compared to its simulated spectrum (top). Peaks in the $550-750 \mathrm{~cm}^{-1}$ window that are readily assigned to furan vibrations are denoted by $\mathrm{F}$.

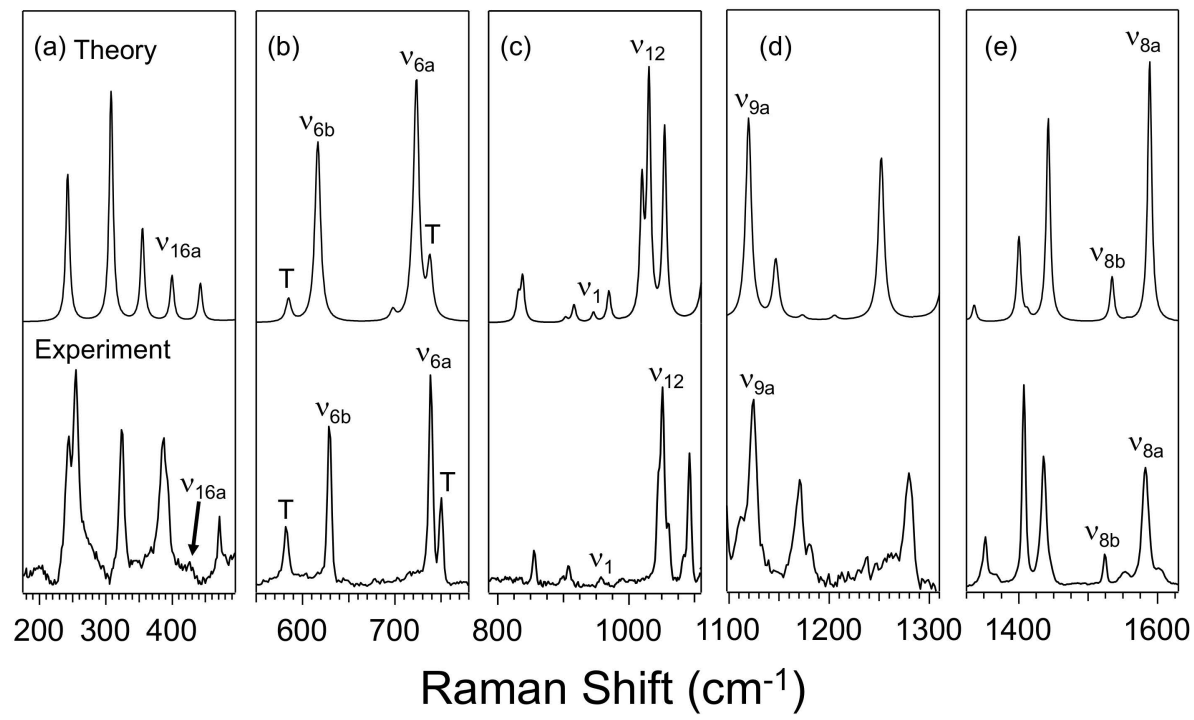

Figure 10. Experimental Raman spectra of PrmT (bottom) compared to its simulated spectrum (top). Peaks in the $550-750 \mathrm{~cm}^{-1}$ window that are readily assigned to thiophene vibrations are denoted by $\mathrm{T}$.

The pairwise interactions present in the co-crystals using the experimentally determined coordinates are also explored through the analyses of dimers constructed with $\left(\mathrm{NO}_{2}\right)_{2} \mathrm{BAI}$ interacting with either PrmF or PrmT. One $\left(\mathrm{NO}_{2}\right)_{2}$ BAI-PrmF complex and one $\left(\mathrm{NO}_{2}\right)_{2}$ BAI-PrmT complex interacting through a halogen bond were also fully optimized, and the resulting simulated Raman spectra are shown in Figures 11 and 12. Figure S7 includes a comparison of the simulated Raman spectra of Prm, PrmF, PrmT, $\left(\mathrm{NO}_{2}\right)_{2}$ BAI-PrmF, $\left(\mathrm{NO}_{2}\right)_{2} \mathrm{BAI}-\mathrm{PrmT}$, and $\left(\mathrm{NO}_{2}\right)_{2} \mathrm{BAI}$. A structural analysis via density functional theory computations at the M06-2X/aVTZ level of theory reveals 13 unique pairwise contacts in the experimental $\left(\mathrm{NO}_{2}\right)_{2} \mathrm{BAI}-\mathrm{PrmF}$ co-crystal (top panel in Figure 4; Figure S3 and Table S22). The homogenous pairwise contacts of either two $\left(\mathrm{NO}_{2}\right)_{2} \mathrm{BAI}$ donors or two PrmF acceptors consist of only weak secondary slipped-stack $\left(E_{\text {int }}^{A v g}=-1.4 \mathrm{kcal} \mathrm{mol}^{-1}\right.$ to $\left.-3.7 \mathrm{kcal} \mathrm{mol}^{-1}\right)$ and antiparallel $\left(E_{\text {int }}^{A v g}=-0.9 \mathrm{kcal} \mathrm{mol}^{-1}\right) \pi$-type interactions. Intermolecular pairwise contacts between a $\left(\mathrm{NO}_{2}\right)_{2} \mathrm{BAI}$ donor and a PrmF acceptor, on the other hand, have stronger interactions and include hydrogen bonding $\left(E_{\text {int }}^{A v g}=-1.1 \mathrm{kcal} \mathrm{mol}^{-1}\right.$ to $\left.-4.0 \mathrm{kcal} \mathrm{mol}^{-1}\right)$ and halogen bonding interactions $\left(E_{\text {int }}^{A v g}=-7.0\right.$ $\mathrm{kcal} \mathrm{mol}^{-1}$ to $\left.-7.1 \mathrm{kcal} \mathrm{mol}^{-1}\right)$. The relatively strong hydrogen bonding interaction $\left(E_{\text {int }}^{A v g}=-4.0 \mathrm{kcal}\right.$ 
mol $^{-1}$; contact (k) in Figure S3) includes two unique hydrogen bonds (i.e., $\mathrm{H}_{\mathrm{A}} \cdots \mathrm{O}_{\mathrm{D}}$ and $\mathrm{H}_{\mathrm{D}} \cdots \mathrm{N}_{\mathrm{A}}$ ). The $\left(\mathrm{NO}_{2}\right)_{2} \mathrm{BAI}$-PrmF co-crystal also exhibits strong heterogenous $\pi$-stacking interactions $\left(E_{\text {int }}^{\text {Avg }}=-6.2\right.$ $\mathrm{kcal} \mathrm{mol}^{-1}$ to $\left.-7.3 \mathrm{kcal} \mathrm{mol}^{-1}\right)$.

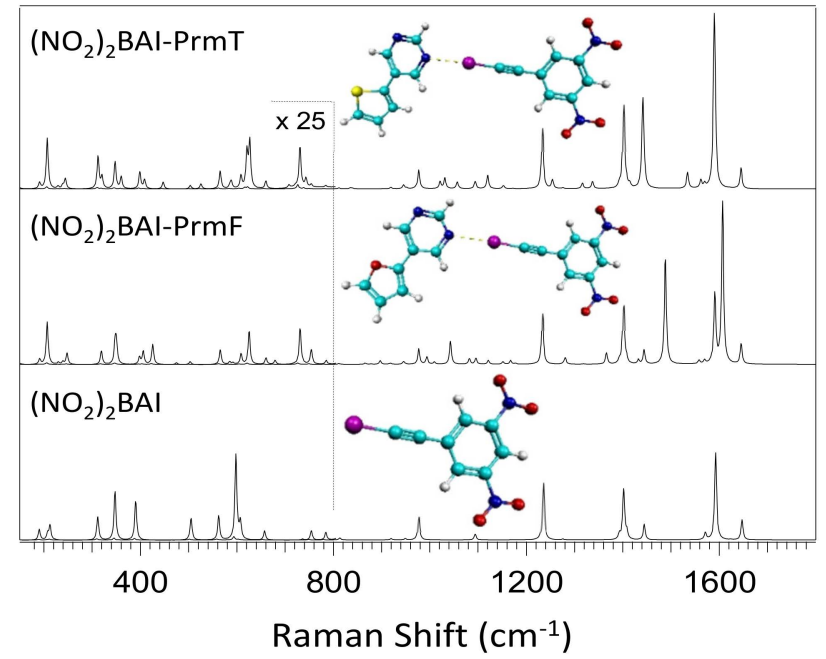

Figure 11. Simulated Raman spectra of $\left(\mathrm{NO}_{2}\right)_{2} \mathrm{BAI}$ (bottom), and optimized complexes formed from $\left(\mathrm{NO}_{2}\right)_{2} \mathrm{BAI}$ with either PrmF (middle) or PrmT (top). Raman activities below $800 \mathrm{~cm}^{-1}$ have been multiplied by a factor of twenty-five so that they can be easily visualized.

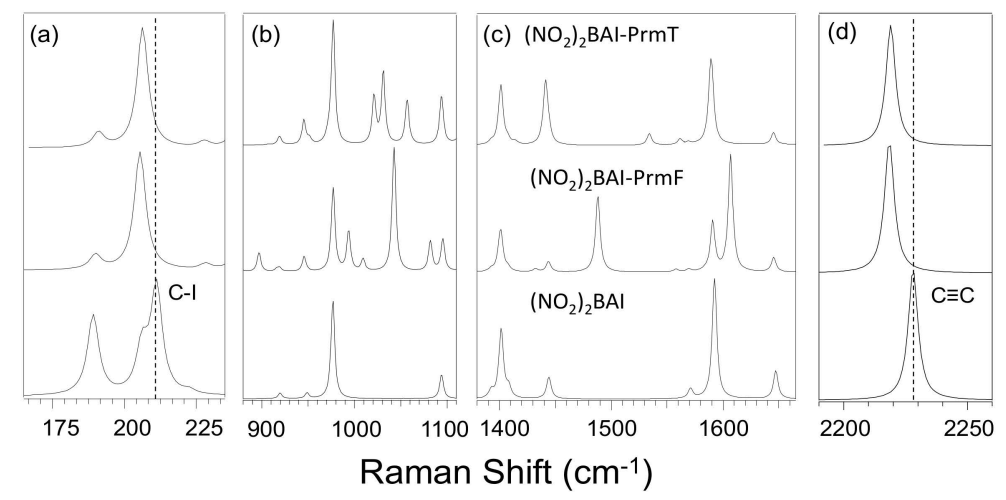

Figure 12. Simulated Raman spectra of $\left(\mathrm{NO}_{2}\right)_{2} \mathrm{BAI}$ (bottom), and co-crystals formed from $\left(\mathrm{NO}_{2}\right)_{2} \mathrm{BAI}$ with either PrmF (middle) or PrmT (top) in different spectral regions.

A structural analysis similar to that performed on the $\left(\mathrm{NO}_{2}\right)_{2} \mathrm{BAI}-\mathrm{PrmF}$ co-crystal was carried out on the experimental $\left(\mathrm{NO}_{2}\right)_{2}$ BAI-PrmT co-crystal (bottom panel in Figure 4; Figure S4 and Table S23). In this case, an added complexity in the form of the crystallographic disorder of the thiophene moieties leads to a greater number of unique pairwise contacts. Homogenous interactions formed between either two $\left(\mathrm{NO}_{2}\right)_{2}$ BAI donors or two PrmT acceptors make up 12 of the 28 pairwise contacts identified, and consist of slipped-stack $\left(E_{\text {int }}^{A v g}=-0.8 \mathrm{kcal} \mathrm{mol}^{-1}\right.$ to $\left.-3.7 \mathrm{kcal} \mathrm{mol}^{-1}\right)$, antiparallel $\left(E_{\text {int }}^{A \text { Avg }}=-0.7 \mathrm{kcal} \mathrm{mol}^{-1}\right.$ to $\left.-1.6 \mathrm{kcal} \mathrm{mol}^{-1}\right)$, and t-shaped $\left(E_{\text {int }}^{A v g}=-2.8 \mathrm{kcal} \mathrm{mol}^{-1}\right.$ to $\left.-3.1 \mathrm{kcal} \mathrm{mol}^{-1}\right) \pi$-type interactions, as well as a hydrogen bonding interaction $\left(E_{\text {int }}^{A v g}=-4.0 \mathrm{kcal} \mathrm{mol}^{-1}\right)$. The remaining sixteen heterogenous pairwise contacts include strong halogen bonding $\left(E_{\text {int }}^{A v g}=-6.8 \mathrm{kcal} \mathrm{mol}^{-1}\right)$ and $\pi$-stacking interactions $\left(E_{\text {int }}^{A v g}=-7.0 \mathrm{kcal} \mathrm{mol}^{-1}\right.$ to $\left.-7.2 \mathrm{kcal} \mathrm{mol}^{-1}\right)$, along with weaker perpendicular $\pi$-type interactions $\left(E_{\text {int }}^{A \text { Avg }}\right.$ $=-1.2 \mathrm{kcal} \mathrm{mol}^{-1}$ to $\left.-3.0 \mathrm{kcal} \mathrm{mol}^{-1}\right)$ and hydrogen bonding interactions $\left(E_{\text {int }}^{A \text { Avg }}=-0.6 \mathrm{kcal} \mathrm{mol}^{-1}\right.$ to $-3.1 \mathrm{kcal} \mathrm{mol}^{-1}$ ). The two strongest hydrogen bonding interactions (with $E_{\text {int }}^{\text {Avg }}$ near $-3 \mathrm{kcal} \mathrm{mol}^{-1}$ ) involve not only a $\mathrm{H}_{\text {donor }} \cdots \mathrm{N}_{\text {Prm }}$ contact, but also an interesting contact between an acidic proton of the pyrimidine moiety, and the $\pi$ electrons in the $\mathrm{C} \equiv \mathrm{C}$ bond connecting the I atom to the benzene ring. 
The other hydrogen bonding interactions present in the $\left(\mathrm{NO}_{2}\right)_{2} \mathrm{BAI}-\mathrm{PrmT}$ co-crystal exhibit $E_{\text {int }}^{\text {Avg }}$ values that are weaker (less negative) by approximately 1 to $2 \mathrm{kcal} \mathrm{mol}^{-1}$. Although these intermolecular interactions are relatively weak, the same cannot be said for the $\pi$-stacking $\left(E_{\text {int }}^{A v g}=-7.0 \mathrm{kcal} \mathrm{mol}^{-1}\right.$ to $\left.-7.2 \mathrm{kcal} \mathrm{mol}^{-1}\right)$ and halogen bonding interactions $\left(E_{\text {int }}^{A v g}=-6.8 \mathrm{kcal} \mathrm{mol}^{-1}\right)$.

\section{Discussion}

\subsection{Effect of Furan and Thiophene Moieties on Pyrimidine's Normal Modes}

Table 2 compares the scaled computed frequencies of Prm and its derivatives PrmF and PrmT, with experimental spectroscopic assignments aided by analyzing the associated atomic displacements. Prm is an azabenzene (heterocyclic nitrogen analogue of benzene), and therefore its normal modes are traditionally named in relation to benzene's normal modes, as introduced by Lord, et al. in 1957 [53]. For example, the highest intensity Raman-active mode in Prm is the ring breathing mode $v_{1}$ at $990 \mathrm{~cm}^{-1}$ in the liquid state, and $992 \mathrm{~cm}^{-1}$ in the solid-state. This mode is sensitive to perturbations of the ring's delocalized electron density due to noncovalent interactions. Although a Fermi resonance (FR) centered at about $1060 \mathrm{~cm}^{-1}$ complicates Prm's vibrational spectrum, the assignment of its normal modes is well established [42], and a comparison the computed and observed features is included in Figure S5. When comparing solid-state vibrational frequencies with those in the liquid or gaseous phases, most normal modes are also usually observed to shift to a higher energy (+ shift) by about $1 \%-2 \%$ when in the solid-state. This is also true for Prm and its derivatives, and results in many of the scaled computed frequencies being smaller than the observed values.

Table 2. Assignment of normal modes in Prm derivatives PrmF and PrmT, and analysis of the degree of coupling with other modes. Frequencies are in $\mathrm{cm}^{-1}$, and computed values have been scaled by 0.956 to account for anharmonicity.

\begin{tabular}{|c|c|c|c|c|}
\hline $\begin{array}{c}\text { Mode in } \\
\text { Pyrimidine }\end{array}$ & Building Block & $\begin{array}{l}\text { Computed } \\
\text { Frequency }\end{array}$ & $\begin{array}{l}\text { Experimental } \\
\text { Frequency }\end{array}$ & $\begin{array}{l}\text { Dominant Motion or } \\
\text { Character }\end{array}$ \\
\hline \multirow{3}{*}{$v_{16 a}$} & Prm & 392 & 400 & \multirow{3}{*}{ Out-of-plane puckering } \\
\hline & PrmF & 394 & 400 & \\
\hline & PrmT & 400 & 425 & \\
\hline \multirow{3}{*}{$v_{6 b}$} & Prm & 606 & 628 & \multirow{3}{*}{$\begin{array}{l}\text { In-plane } \mathrm{CCC} / \mathrm{NCN} \\
\text { bending mode }\end{array}$} \\
\hline & PrmF & 614 & 630 & \\
\hline & PrmT & 615 & 629 & \\
\hline \multirow{3}{*}{$v_{6 a}$} & Prm & 667 & 680 & \multirow{3}{*}{$\begin{array}{l}\text { In-plane CCC/CNC } \\
\text { bending mode }\end{array}$} \\
\hline & PrmF & 722 & 736 & \\
\hline & PrmT & 723 & 739 & \\
\hline \multirow{3}{*}{$v_{1}$} & Prm & 980 & 992 & \multirow{3}{*}{ Ring breathing } \\
\hline & PrmF & 895 & 907 & \\
\hline & PrmT & 946 & 957 & \\
\hline \multirow{3}{*}{$v_{12}$} & Prm & - & - & \multirow{3}{*}{ Ring bending } \\
\hline & PrmF & 1043 & 1060 & \\
\hline & PrmT & 1030 & 1051 & \\
\hline \multirow{3}{*}{$v_{9 a}$} & Prm & 1126 & 1142 & \multirow{3}{*}{ NCN bend } \\
\hline & PrmF & 1121 & 1125 & \\
\hline & PrmT & 1120 & 1125 & \\
\hline \multirow{3}{*}{$v_{8 b}$} & Prm & 1582 & 1577 & \multirow{3}{*}{$\mathrm{CN}$ stretch } \\
\hline & PrmF & $1557 / 1579$ & $1555 / 1569$ & \\
\hline & PrmT & 1556 & 1553 & \\
\hline \multirow{3}{*}{$v_{8 a}$} & Prm & 1584 & 1568 & \multirow{3}{*}{$\mathrm{CC}$ and $\mathrm{CN}$ stretch } \\
\hline & PrmF & 1606 & 1598 & \\
\hline & PrmT & 1589 & 1583 & \\
\hline
\end{tabular}




\subsubsection{Ring Puckering Mode $v_{16 a}$}

We previously showed that the out of plane puckering mode $v_{16 a}$ split from one peak in the liquid, to two peaks (a major and a minor) in the solid-state, but did not shift its location [44]. A comparison of the computed locations for this mode between Prm, PrmF, and PrmT, in Figure 8, predicts a slight shift to a higher energy of $2 \mathrm{~cm}^{-1}$ and $8 \mathrm{~cm}^{-1}$ when adding the furan and thiophene moieties, respectively. Comparisons of the number and intensities of features in the simulated spectra in Figures 9a and 10a suggest that $v_{16 a}$ lies at $400 \mathrm{~cm}^{-1}$ in PrmF and $425 \mathrm{~cm}^{-1}$ in PrmT experimentally. Compared to all of the other modes in this study, $v_{16 a}$ exhibits the smallest degree of coupling with other motions. Other modes in the vicinity of $v_{16 a}$ in both PrmF and PrmT involve the motions of both rings. The most Raman active peak in PrmF in this region at $358 \mathrm{~cm}^{-1}$ involves the stretching of the covalent bond between the two rings. The same feature appears experimentally in $\operatorname{PrmT}$ at $324 \mathrm{~cm}^{-1}$.

\subsubsection{Ring Bending Modes $v_{6 \mathrm{~b}}$ and $v_{6 \mathrm{a}}$}

Figure 3b, Figure 9b, Figure 10b, and Figure S5 show the spectral features in the vicinity of Prm's in-plane bending modes $v_{6 \mathrm{~b}}$ and $v_{6 \mathrm{a}}$. The agreement between experiment and theory in this region is very good, making assignments straightforward. In benzene, these modes are degenerate, but they are split in Prm because of the replacement of two carbon atoms with nitrogen atoms. These modes lie at $628 \mathrm{~cm}^{-1}$ and $680 \mathrm{~cm}^{-1}$, respectively, in crystalline Prm, and are predicted computationally to shift to higher energy in both isolated PrmF and PrmT molecules. A comparison of the spectral features in Figures $9 \mathrm{~b}$ and $10 \mathrm{~b}$ reveals that $v_{6 \mathrm{~b}}$ and $v_{6 \mathrm{a}}$ lie at $630 \mathrm{~cm}^{-1}$ and $736 \mathrm{~cm}^{-1}$ in PrmF, and $629 \mathrm{~cm}^{-1}$ and $739 \mathrm{~cm}^{-1}$ in PrmT, respectively. Interestingly, although $v_{6 \mathrm{~b}}$ is at essentially the same energy in all three cases, $v_{6 a}$ shifts to a higher energy by over $50 \mathrm{~cm}^{-1}$ from Prm to its derivatives. This is most likely due to the presence of the furan and thiophene rings at Prm's para position, and the unavoidable coupling of $v_{6 a}$ with similar bending modes in each.

\subsubsection{Fermi Resonance and Ring Breathing Modes $v_{1}$ and $v_{12}$}

Figure 3c, Figure 9c, Figure 10c, and Figure S5 show spectral features in the vicinity of Prm's Fermi resonance composed of $v_{12}$ and the combination band $\left(v_{10 \mathrm{~b}}\right.$ and $\left.v_{16 \mathrm{~b}}\right)$, and its ring breathing mode $v_{1}$. This latter spectral feature dominates the Raman spectra of liquid, solution, and solid phase, and we have shown previously that it is very sensitive to hydrogen bonding [42,43,45], halogen bonding [21], and the transfer of electron density [48]. Contrary to the other spectral regions considered here, there are few similarities in the spectral features between Prm and its derivatives. A comparison of the experimental solid state and individual molecule simulated spectra for PrmF and PrmT reveals a surprisingly good agreement, despite the possible presence of FR. This could be due to the aromaticity of these molecules, and the large charge redistribution that occurs when ring symmetric and asymmetric stretches occur or the changes in frequencies off-resonance due to the larger masses of the molecules. At first glance, Prm's most intense and signature Raman spectral feature, $v_{1}$, which usually is present at approximately $990 \mathrm{~cm}^{-1}$, appears to be totally absent in both PrmF and PrmT. An analysis of the normal mode displacements reveals a strong mixing of ring stretching motions in this region, with motions by either furan or thiophene. It turns out that Prm's mode, $v_{1}$, is strongly coupled to furan's and thiophene's ring breathing motions, and as a result, is red shifted (decreased in energy) by about $90 \mathrm{~cm}^{-1}$ in PrmF to $907 \mathrm{~cm}^{-1}$ and $40 \mathrm{~cm}^{-1}$ in PrmT to $957 \mathrm{~cm}^{-1}$, compared to predictions of $895 \mathrm{~cm}^{-1}$ and $946 \mathrm{~cm}^{-1}$, respectively. Prm's prominent and sensitive [48] FR also seems mostly absent in these derivatives, and in its place are strongly coupled features involving Prm's $v_{12}$ at $1060 \mathrm{~cm}^{-1}$ in PrmF and $1051 \mathrm{~cm}^{-1}$ in PrmT compared to the scaled predictions of $1043 \mathrm{~cm}^{-1}$ and $1030 \mathrm{~cm}^{-1}$, respectively.

\subsubsection{NCN Bending Mode $v_{9 a}$ and In-Plane $\mathrm{CH}$ Bending Mode $v_{3}$}

Unlike the strong coupling observed with Prm's mode ring breathing mode $v_{1}, v_{9 a}$ is largely localized and easily located at $1125 \mathrm{~cm}^{-1}$ in both PrmF and PrmT, compared to the predicted energies of 
$1121 \mathrm{~cm}^{-1}$ and $1120 \mathrm{~cm}^{-1}$, respectively. The $\mathrm{C}-\mathrm{H}$ bending mode, $v_{3}$, however, does not exist in its pure form in the derivatives considered here, as one of the hydrogen atoms is replaced with the addition of the furan or thiophene groups. The comparable mode with the bending of just three hydrogen atoms in PrmF is expected computationally at $1318 \mathrm{~cm}^{-1}$ and $1316 \mathrm{~cm}^{-1}$ in PrmT. The feature is expected to be rather Raman inactive, however. Many of the features in this region are also strongly coupled with either furan or thiophene hydrogen atom bending motions.

\subsubsection{Symmetric and Asymmetric CN Stretching Modes $v_{8 a}$ and $v_{8 b}$}

The symmetric and asymmetric $\mathrm{CN}$ stretching modes, $v_{8 \mathrm{a}}$ and $v_{8 \mathrm{~b}}$, respectively, are nearly isoenergetic in the liquid state at approximately $1565 \mathrm{~cm}^{-1}$. Whereas $v_{8 a}$ is not significantly perturbed by hydrogen bonding [42,43,45], halogen bonding [21], and electron density redistribution [48], $v_{8 \mathrm{~b}}$ is very sensitive to intermolecular interactions, and is to observed to significantly blue-shift in a similar fashion to $v_{1}$. We previously took advantage of this phenomenon and employed hydrogen bonding with water to separate the two modes in a solution and confirm their assignments [42]. In the solid-state, $v_{8 \mathrm{a}}$ in Prm is observed to split into two peaks of the same intensity, and $v_{8 \mathrm{~b}}$ blue-shifts to $1577 \mathrm{~cm}^{-1}$, as shown in Figure 3. Our computations indicated these two modes are well resolved in both derivatives, and the energetic order of $v_{8 \mathrm{a}}$ and $v_{8 \mathrm{~b}}$ is, in fact, predicted to invert in PrmF and PrmT, relative to Prm, as shown in Figures 9e and 10e. In the case of PrmF, $v_{8 \mathrm{~b}}$ is expected to be manifested as two low intensity modes at $1557 \mathrm{~cm}^{-1}$ and $1579 \mathrm{~cm}^{-1}$, and two modes matching this prediction are indeed experimentally observed at $1555 \mathrm{~cm}^{-1}$ and $1569 \mathrm{~cm}^{-1}$. In the case of PrmT, one peak at $1556 \mathrm{~cm}^{-1}$ is expected, and experimentally one at $1553 \mathrm{~cm}^{-1}$ is observed. The assignment of $v_{8 \mathrm{a}}$ (symmetric stretching motion) in both molecules is more straightforward, with strong Raman active features predicted at energies of $1606 \mathrm{~cm}^{-1}$ and $1589 \mathrm{~cm}^{-1}$ in PrmF and PrmT, respectively. Experimentally, intense features existing at $1598 \mathrm{~cm}^{-1}$ and $1583 \mathrm{~cm}^{-1}$ are readily observed in the two molecules.

\subsection{Effect of Halogen Bond Interactions on Raman Spectral Features}

As pointed out earlier, although both crystals possess slipped-stack $\pi-\pi$ arrangements, PrmF forms continuous stacked sheets interacting through $\pi-\pi$ forces, whereas, PrmT does not. The former is due to weak secondary hydrogen bonding, resulting from acidic protons on both the pyrimidine and furan moieties, interacting with nitro oxygen atoms on $\left(\mathrm{NO}_{2}\right)_{2}$ BAI. These results suggest that an interplay between the $\pi$-stacking and halogen bonding interactions within the $\left(\mathrm{NO}_{2}\right)_{2} \mathrm{BAI}$-PrmF co-crystal drive molecular assembly in these systems.

Figure 6, Figure 11, and Figure 12 show the experimental and simulated Raman spectra, respectively, of the co-crystals in the spectral regions of the C-I stretch in $\left(\mathrm{NO}_{2}\right)_{2} \mathrm{BAI}, v_{1}$, and $v_{12}$, and also $v_{8 \mathrm{a}}$ and $v_{8 \mathrm{~b}}$. The bond length and frequency of vibration involving the halogen atom in the halogen bond donors has been demonstrated previously to be a sensitive probe of halogen bond interactions. For example, we showed that the $\mathrm{C}-\mathrm{I}$ stretch in $\left(\mathrm{NO}_{2}\right)_{2} \mathrm{BAI}$ is normally at $203 \mathrm{~cm}^{-1}$ in the solid state, but is red-shifted when participating in strong halogen bonding interactions [18]. Computationally, the C-I stretch is predicted to shift here by $7 \mathrm{~cm}^{-1}$ from $213 \mathrm{~cm}^{-1}$ in isolated $\left(\mathrm{NO}_{2}\right)_{2} \mathrm{BAI}$, to $206 \mathrm{~cm}^{-1}$ in both optimized complexes. In the experimental $\left(\mathrm{NO}_{2}\right)_{2} \mathrm{BAI}-\mathrm{PrmF}$ co-crystal studied here, however, although the $\mathrm{C}-\mathrm{I}$ stretch is easily identifiable, no apparent shift is induced by the formation of the halogen bond. The same is true in $\left(\mathrm{NO}_{2}\right)_{2} \mathrm{BAI}-\mathrm{PrmT}$, but surprisingly, a new mode at $193 \mathrm{~cm}^{-1}$ appears in the Raman spectrum. It turns out that in the crystal structure of $\left(\mathrm{NO}_{2}\right)_{2} \mathrm{BAI}-\mathrm{PrmT}$, the PrmT fragment actually adopts two unique poses that effectively differ by a $\approx 180^{\circ}$ rotation of the thiophene moiety about the $\mathrm{C}-\mathrm{C}$ bond, connecting the 5 - and 6-membered rings.

Modes associated with the motions of the nitrogen atoms in PrmF and PrmT are expected to be most perturbed from halogen bond interactions with $\left(\mathrm{NO}_{2}\right)_{2} \mathrm{BAI}$, because of their sensitivity to charge redistribution and bond length changes. We previously showed that, when Prm participates in halogen bonded interactions with iodopentafluorobenzene, $v_{1}$ blue-shifts by $5 \mathrm{~cm}^{-1}$ and $v_{8 \mathrm{~b}}$ by 6 $\mathrm{cm}^{-1}$ [21]. Experimentally, in $\left(\mathrm{NO}_{2}\right)_{2}$ BAI-PrmF, $v_{1}$ remains essentially unchanged at $908 \mathrm{~cm}^{-1}$, but $v_{12}$ 
red-shifts $6 \mathrm{~cm}^{-1}$ to $1054 \mathrm{~cm}^{-1}$. Computationally, $v_{1}$ is expected to blue-shift by $2 \mathrm{~cm}^{-1}$, but $v_{12}$ is not expected to change. In $\left(\mathrm{NO}_{2}\right)_{2} \mathrm{BAI}-\mathrm{PrmT}, v_{1}$ is unfortunately not discernable, but $v_{12}$ again red-shifts 6 $\mathrm{cm}^{-1}$ to $1045 \mathrm{~cm}^{-1}$. Computationally, however, $v_{1}$ is expected to blue-shift by $6 \mathrm{~cm}^{-1}$, and $v_{12}$ remains unchanged. No discernable effects are observed experimentally on $v_{8 \mathrm{a}}$ or $v_{8 \mathrm{~b}}$. Computationally, in $\left(\mathrm{NO}_{2}\right)_{2} \mathrm{BAI}-\mathrm{PrmF}, v_{8 \mathrm{a}}$ remains essentially unchanged, but $v_{8 \mathrm{~b}}$ is expected to have a $4 \mathrm{~cm}^{-1}$ blue-shift. In $\left(\mathrm{NO}_{2}\right)_{2} \mathrm{BAI}-\mathrm{PrmT}, v_{8 \mathrm{a}}$ again is predicted to remain unchanged, but $v_{8 \mathrm{~b}}$ is predicted to exhibit a $5 \mathrm{~cm}^{-1}$ blue-shift. This apparent disagreement between the experiment and theory is likely attributable to the fact that we are only computationally considering 1:1 complexes that have been re-optimized, and that we are ignoring other solid-state environmental effects that are known to exist in the co-crystals [18,21].

\section{Materials and Methods}

\subsection{Synthesis and Co-Crystallization}

The halogen acceptors and donors were synthesized according to modified literature procedures (Supplementary Materials) [54,55]. The co-crystals were prepared in duplicate at a 2:1 ratio by dissolving each acceptor $(3.0 \mathrm{mg})$ separately in a chlorinated solvent $(1.25 \mathrm{~mL}$, dichloromethane or chloroform), and adding it dropwise to a borosilicate glass vial $(1.2 \times 4.4 \mathrm{~cm}$, diameter and height containing the donor (11-12 mg) in $1 \mathrm{~mL}$ of solvent. The resulting mixtures were ultrasonicated for $10 \mathrm{~min}$. The open vial was placed in a secondary vial $(2.5 \times 5.5 \mathrm{~cm})$ containing $n$-hexane $(3 \mathrm{~mL})$. Using vapor diffusion methods, crystals were allowed to form at $-5^{\circ} \mathrm{C}$ over 14 days. Confirmation of the co-crystallization was observed through a $\sim 10{ }^{\circ} \mathrm{C}$ difference in melting points between the co-crystals and the acceptor.

PrmF and $\left(\mathrm{NO}_{2}\right)_{2} \mathrm{BAI}: \mathrm{C}_{16} \mathrm{H}_{9} \mathrm{IN}_{4} \mathrm{O}_{5}(\mathrm{M}=464.17 \mathrm{~g} / \mathrm{mol})$ : triclinic, space group P $\overline{1}, a=6.9398(10) \AA$, $b=16.126(2) \AA, c=18.517(3) \AA, \alpha=79.340(4)^{\circ}, \beta=80.010(4)^{\circ}, \gamma=89.242(4)^{\circ}, V=2005.2(5) \AA^{3}, Z=4$, $T=100.0 \mathrm{~K}, \mu(\mathrm{Mo} \mathrm{K} \alpha)=1.628 \mathrm{~mm}^{-1}, D_{\text {calc }}=1.538 \mathrm{Mg} / \mathrm{m}^{3}, 22950$ reflections measured $\left(1.55^{\circ} \leq 2 \theta \leq\right.$ $\left.26.5^{\circ}\right), 8062$ unique $\left(R_{\text {int }}=0.0516, R_{\text {sigma }}=0.0296\right)$, which were used in all of the calculations. The final $R_{1}$ was $0.0484(I \geq 2 \sigma(I))$ and $w R_{2}$ was 0.1220 (all data).

PrmT and $\left(\mathrm{NO}_{2}\right)_{2}$ BAI: $\mathrm{C}_{32} \mathrm{H}_{18} \mathrm{I}_{2} \mathrm{~N}_{8} \mathrm{O}_{8} \mathrm{~S}_{2}(\mathrm{M}=960.46 \mathrm{~g} / \mathrm{mol})$ : monoclinic, space group P $21 / \mathrm{n}, a=$ 9.2195(6) $\AA, b=5.7344(4) \AA, c=32.1204(16) \AA, \alpha=90^{\circ}, \beta=93.209(3)^{\circ}, \gamma=90^{\circ}, V=1695.49(18) \AA^{3}, \mathrm{Z}=$ $2, T=100.0 \mathrm{~K}, \mu(\mathrm{Mo} \mathrm{K} \alpha)=2.043 \mathrm{~mm}^{-1}, D_{\text {calc }}=1.881 \mathrm{Mg} / \mathrm{m}^{3}, 14426$ reflections measured $\left(2.27^{\circ} \leq 2 \theta \leq\right.$ $\left.28.3^{\circ}\right), 4232$ unique $\left(R_{\text {int }}=0.0722, R_{\text {sigma }}=0.0296\right)$, which were used in all of the calculations. The final $R_{1}$ was $0.0438(I \geq 2 \sigma(I))$ and $\mathrm{w} R_{2}$ was 0.1040 (all data).

\subsection{Spectroscopic Details}

A Horiba Scientific LabRAM HR Evolution Raman Spectroscopy system (Horiba Scientific, Kyoto, Japan) was used for the acquisition of the Raman spectra. The $532 \mathrm{~nm}$ line from a Nd:YAG laser (Oxxius, Lannion, France) was focused onto solid samples using a 100× objective with a 0.9 NA and a 1800 grooves/mm grating, and CCD camera were used for detection.

\subsection{Computational Details}

Full geometry optimizations and harmonic vibrational frequency computations with IR intensities and Raman activities were performed on the halogen bond donor $\left(\left(\mathrm{NO}_{2}\right)_{2} \mathrm{BAI}\right)$, acceptors (PrmF and PrmT $)$, and the corresponding pairwise complexes $\left(\left(\mathrm{NO}_{2}\right)_{2}\right.$ BAI-PrmF and $\left(\mathrm{NO}_{2}\right)_{2}$ BAI-PrmT). The fully optimized geometries and the corresponding harmonic vibrational frequencies of the dimer complexes and the corresponding fragments were used not only to verify whether each structure was a minimum (i.e., $n_{i}=0$ ) on the potential energy surface, but also to compare to the experimental Raman spectra. A set of single point energy computations, with and without the Boys-Bernardi counterpoise (CP) procedure $[56,57]$ was performed on the pairwise contacts found in the experimental halogen bond crystal structures, in order to determine their interaction energies $\left(E_{\mathrm{int}}=E_{\text {complex }}^{\mathrm{xtal}}-E_{\mathrm{donor}}^{\mathrm{xtal}}-E_{\mathrm{acceptor}}^{\mathrm{xtal}}\right)$. 
All of the computations were performed using the Gaussian 09 software package (Gaussian, Inc, Wallingford, CT, USA) and, where applicable, the analytic gradients and Hessians available therein [58]. The geometry optimizations and vibrational frequency computations all used the global hybrid M06-2X [59] density functional in conjunction with a triple- $\zeta$ quality correlation consistent basis set augmented with diffuse functions on all of the atoms, and a relativistic pseudopotential on iodine centers (aug-cc-pVTZ [60-62] for H, C, N, O, F, S, and aug-cc-pVTZ-PP [63,64] for I; denoted aVTZ). These prescriptions were employed based on the extensive calibration Kozuch and Martin [65]. All of the reported $E_{\text {int }}$ values are determined using the average of the necessary electronic energies (with and without CP corrections) at the M06-2X/aVTZ level of theory. All of the computations were performed using a pruned numerical integration grid composed of 175 radial shells ( 250 radial shells for sulfur and iodine atoms) and 974 angular points per shell, along with a threshold of $<10^{-9}$ for the RMS change in the density matrix during the self-consistent field procedure. The threshold for removing the linear dependent basis functions (magnitude of the eigenvalues of the overlap matrix) was tightened from $10^{-6}$ to $10^{-7}$. All of the electronic energies were converged to at least $10^{-9} \mathrm{E}_{h}$, while the Cartesian forces of the gradient did not exceed $10^{-5} \mathrm{E}_{h} \mathrm{a}_{0}{ }^{-1}$. Furthermore, pure angular momentum (i.e., $5 d, 7 f$, etc.) basis functions were used instead of their Cartesian counterparts (i.e., $6 d, 10 f$, etc.). The optimized Cartesian coordinates and harmonic vibrational frequencies with IR intensities, and the Raman activities of each halogen bond donor, acceptor, and halogen bonded complex can be found in the Supporting Information.

\subsection{X-ray Crystallography}

Crystal evaluation and data collection were performed on a Bruker Kappa diffractometer (Bruker, Madison, WI, USA) with Mo $\mathrm{K} \alpha(\lambda=0.71073 \AA)$ radiation. The reflections were indexed by an automated indexing routine built in the APEXII program suite. The solution and refinement were carried out in Olex2 version 1.2 using the program SHELXTL [66,67]. Non-hydrogen atoms were refined with anisotropic thermal parameters, while hydrogen atoms were introduced at calculated positions based on their carrier/parent atoms. The crystal data and structure refinement parameters for all of the compounds are given in the Supplementary Materials. The CCDC numbers for the single crystal X-ray structures of each co-crystal are as follows: 1954813 and 1954814.

\section{Conclusions}

The modification of Prm with either a furan or a thiophene moiety affects only a select few of the normal modes of Prm. Most noticeably, Prm's signature ring breathing mode, $v_{1}$, couples with motions in furan and thiophene, and essentially disappears as an isolated mode. A total of 13 and 28 unique pairwise contacts were discovered in the experimental $\left(\mathrm{NO}_{2}\right)_{2} \mathrm{BAI}-\mathrm{PrmF}$ and $\left(\mathrm{NO}_{2}\right)_{2} \mathrm{BAI}-\mathrm{PrmT}$ co-crystals. The added complexity in the thiophene derivative stems from a crystallographic disorder in its structure. In both cases, $\pi$-stacking and halogen bonding interactions dominate the interactions, with interaction energies ranging between 6 and $7 \mathrm{kcal} \mathrm{mol}^{-1}$ in the various computed structures. Although the $\mathrm{C}-\mathrm{I}$ and $\mathrm{C} \equiv \mathrm{C}$ halogen bond donor stretches experiences red-shifts as expected, surprisingly, the creation of individual pairwise halogen bonds did not seem to significantly affect the vibrational spectra of these new derivatized acceptors, as observed previously for Prm.

Supplementary Materials: The following are available online at http://www.mdpi.com/2304-6740/7/10/119/s1: The CIFs and CheckCIFs; synthesis details; NMR spectra; crystal data and refinement; computational results; Raman spectroscopic data.

Author Contributions: D.L.W. and S.T.N. designed and synthesized the monomers and co-crystals. A.E.S.H. and N.I.H. performed the Raman spectroscopic studies. T.L.E. and G.S.T. performed the quantum chemical calculations. A.L.R. acquired the crystal structures of the halogen-bonded complexes.

Funding: S.T.N. and D.L.W. appreciate financial support for this work from the National Science Foundation CAREER Award, under grant number CHE-1652094. A.E.S.H. and N.I.H. appreciate financial support for this work from the National Science Foundation, under grant number OIA-1539035. T.L.E. and G.S.T. acknowledge support 
from the National Science Foundation, under grant number CHE-1664998, and the computational resources provided by the Mississippi Center for Super-computing Research.

Conflicts of Interest: The authors declare no conflict of interest.

\section{References}

1. Jheng, J.-F.; Lai, Y.-Y.; Wu, J.-S.; Chao, Y.-H.; Wang, C.-L.; Hsu, C.-S. Influences of the Non-Covalent Interaction Strength on Reaching High Solid-State Order and Device Performance of a Low Bandgap Polymer with Axisymmetrical Structural Units. Adv. Mater. 2013, 25, 2445-2451. [CrossRef] [PubMed]

2. Wang, D.; Tong, G.; Dong, R.; Zhou, Y.; Shen, J.; Zhu, X. Self-assembly of supramolecularly engineered polymers and their biomedical applications. Chem. Commun. 2014, 50, 11994-12017. [CrossRef] [PubMed]

3. Nguyen, T.L.; Choi, H.; Ko, S.J.; Uddin, M.A.; Walker, B.; Yum, S.; Jeong, J.E.; Yun, M.H.; Shin, T.J.; Hwang, S.; et al. Semi-crystalline photovoltaic polymers with efficiency exceeding $9 \%$ in a $~ 300 \mathrm{~nm}$ thick conventional single-cell device. Energy Environ. Sci. 2014, 7, 3040-3051. [CrossRef]

4. Feringán, B.; Romero, P.; Serrano, J.L.; Folcia, C.L.; Etxebarria, J.; Ortega, J.; Termine, R.; Golemme, A.; Giménez, R.; Sierra, T. H-Bonded Donor-Acceptor Units Segregated in Coaxial Columnar Assemblies: Toward High Mobility Ambipolar Organic Semiconductors. J. Am. Chem. Soc. 2016, 138, 12511-12518. [CrossRef] [PubMed]

5. Fang, R.; Chen, R.; Gao, J.; Zhang, H.; Wu, H.; Li, H. Chalcogen bridged pyrene derivatives: Synthesis, crystal-packing structures and field effect transistors properties. Org. Electron. 2017, 45, 108-114. [CrossRef]

6. Liu, H.; Huang, L.; Cheng, X.; Hu, A.; Xu, H.; Chen, L.; Chen, Y. N-type Self-Doping of Fluorinate Conjugated Polyelectrolytes for Polymer Solar Cells: Modulation of Dipole, Morphology, and Conductivity. Acs Appl. Mater. Interfaces 2017, 9, 1145-1153. [CrossRef] [PubMed]

7. Metrangolo, P.; Meyer, F.; Pilati, T.; Resnati, G.; Terraneo, G. Halogen Bonding in Supramolecular Chemistry. Angew. Chem. Int. Ed. 2008, 47, 6114-6127. [CrossRef]

8. Abate, A.; Biella, S.; Cavallo, G.; Meyer, F.; Neukirch, H.; Metrangolo, P.; Pilati, T.; Resnati, G.; Terraneo, G. Halide anions driven self-assembly of haloperfluoroarenes: Formation of one-dimensional non-covalent copolymers. J. Fluor. Chem. 2009, 130, 1171-1177. [CrossRef]

9. Cariati, E.; Cavallo, G.; Forni, A.; Leem, G.; Metrangolo, P.; Meyer, F.; Pilati, T.; Resnati, G.; Righetto, S.; Terraneo, G.; et al. Self-Complementary Nonlinear Optical-Phores Targeted to Halogen Bond-Driven Self-Assembly of Electro-Optic Materials. Cryst. Growth Des. 2011, 11, 5642-5648. [CrossRef]

10. Marti-Rujas, J.; Colombo, L.; Lu, J.; Dey, A.; Terraneo, G.; Metrangolo, P.; Pilati, T.; Resnati, G. Hydrogen and halogen bonding drive the orthogonal self-assembly of an organic framework possessing 2D channels. Chem. Commun. 2012, 48, 8207-8209. [CrossRef]

11. Priimagi, A.; Cavallo, G.; Metrangolo, P.; Resnati, G. The Halogen Bond in the Design of Functional Supramolecular Materials: Recent Advances. Acc. Chem. Res. 2013, 46, 2686-2695. [CrossRef] [PubMed]

12. Vasylyeva, V.; Nayak, S.K.; Terraneo, G.; Cavallo, G.; Metrangolo, P.; Resnati, G. Orthogonal halogen and hydrogen bonds involving a peptide bond model. CrystEngComm 2014, 16, 8102-8105. [CrossRef] [PubMed]

13. Mukherjee, A.; Tothadi, S.; Desiraju, G.R. Halogen Bonds in Crystal Engineering: Like Hydrogen Bonds yet Different. Acc. Chem. Res. 2014, 47, 2514-2524. [CrossRef] [PubMed]

14. Wilson, J.; Dal Williams, J.S.; Petkovsek, C.; Reves, P.; Jurss, J.W.; Hammer, N.I.; Tschumper, G.S.; Watkins, D.L. Synergistic effects of halogen bond and $\pi-\pi$ interactions in thiophene-based building blocks. RSC Adv. 2015, 5, 82544-82548. [CrossRef]

15. Vanderkooy, A.; Taylor, M.S. Solution-Phase Self-Assembly of Complementary Halogen Bonding Polymers. J. Am. Chem. Soc. 2015, 137, 5080-5086. [CrossRef]

16. Bushuyev, O.S.; Tan, D.; Barrett, C.J.; Friscic, T. Fluorinated azobenzenes with highly strained geometries for halogen bond-driven self-assembly in the solid state. CrystEngComm 2015, 17, 73-80. [CrossRef]

17. Nguyen, S.T.; Rheingold, A.L.; Tschumper, G.S.; Watkins, D.L. Elucidating the Effects of Fluoro and Nitro Substituents on Halogen Bond Driven Assemblies of Pyridyl-Capped $\pi$-Conjugated Molecules. Cryst. Growth Des. 2016, 16, 6648-6653. [CrossRef]

18. Nguyen, S.T.; Ellington, T.L.; Allen, K.E.; Gorden, J.D.; Rheingold, A.L.; Tschumper, G.S.; Hammer, N.I.; Watkins, D.L. Systematic Experimental and Computational Studies of Substitution and Hybridization Effects in Solid-State Halogen Bonded Assemblies. Cryst. Growth Des. 2018, 18, 3244-3254. [CrossRef] 
19. Johnson, S.N.; Ellington, T.L.; Ngo, D.T.; Nevarez, J.L.; Sparks, N.; Rheingold, A.L.; Watkins, D.L.; Tschumper, G.S. Probing non-covalent interactions driving molecular assembly in organo-electronic building blocks. CrystEngComm 2019, 21, 3151-3157. [CrossRef]

20. Desiraju, G.R.; Shing Ho, P.; Kloo, L.; Legon, A.C.; Marquardt, R.; Metrangolo, P.; Politzer, P.; Resnati, G.; Rissanen, K. Definition of the halogen bond (IUPAC recommendations 2013). Pure Appl. Chem. 2013, 85, 1711-1713. [CrossRef]

21. Ellington, T.L.; Reves, P.L.; Simms, B.L.; Wilson, J.L.; Watkins, D.L.; Tschumper, G.S.; Hammer, N.I. Quantifying the Effects of Halogen Bonding by Haloaromatic Donors on the Acceptor Pyrimidine. ChemPhysChem 2017, 18, 1267-1273. [CrossRef]

22. Huang, Y.; Wang, Z.; Chen, Z.; Zhang, Q. Organic Cocrystals: Beyond Electrical Conductivities and Field-Effect Transistors (FETs). Angew. Chem. Int. Ed. 2019, 58, 9696-9711. [CrossRef] [PubMed]

23. Metrangolo, P.; Resnati, G.; Pilati, T.; Liantonio, R.; Meyer, F. Engineering functional materials by halogen bonding. J. Polym. Sci. Part. A Polym. Chem. 2007, 45, 1-15. [CrossRef]

24. Cavallo, G.; Metrangolo, P.; Milani, R.; Pilati, T.; Priimagi, A.; Resnati, G.; Terraneo, G. The Halogen Bond. Chem. Rev. 2016, 116, 2478-2601. [CrossRef] [PubMed]

25. Weldeab, A.O.; Steen, A.; Starkenburg, D.J.; Williams, J.S.D.; Abboud, K.A.; Xue, J.; Hammer, N.I.; Castellano, R.K.; Watkins, D.L. Tuning the structural and spectroscopic properties of donor-acceptor-donor oligomers via mutual X-bonding, H-bonding, and $\pi-\pi$ interactions. J. Mater. Chem. C 2018, 6, 11992-12000. [CrossRef]

26. Baumann, A.; Cheema, H.; Sabuj, M.A.; McNamara, L.E.; Zhang, Y.; Peddapuram, A.; Nguyen, S.T.; Watkins, D.L.; Hammer, N.I.; Rai, N.; et al. Iodine binding with thiophene and furan based dyes for DSCs. Phys. Chem. Chem. Phys. 2018, 20, 17859-17870. [CrossRef] [PubMed]

27. Simon, S.J.C.; Parlane, F.G.L.; Swords, W.B.; Kellett, C.W.; Du, C.; Lam, B.; Dean, R.K.; Hu, K.; Meyer, G.J.; Berlinguette, C.P. Halogen Bonding Promotes Higher Dye-Sensitized Solar Cell Photovoltages. J. Am. Chem. Soc. 2016, 138, 10406-10409. [CrossRef]

28. Zhu, W.; Zheng, R.; Zhen, Y.; Yu, Z.; Dong, H.; Fu, H.; Shi, Q.; Hu, W. Rational Design of Charge-Transfer Interactions in Halogen-Bonded Co-crystals toward Versatile Solid-State Optoelectronics. J. Am. Chem. Soc. 2015, 137, 11038-11046. [CrossRef] [PubMed]

29. Zhuo, M.-P.; Tao, Y.-C.; Wang, X.-D.; Wu, Y.; Chen, S.; Liao, L.-S.; Jiang, L. 2D Organic Photonics: An Asymmetric Optical Waveguide in Self-Assembled Halogen-Bonded Cocrystals. Angew. Chem. 2018, 130, 11470-11474. [CrossRef]

30. Gidron, O.; Diskin-Posner, Y.; Bendikov, M. $\alpha$-Oligofurans. J. Am. Chem. Soc. 2010, 132, 2148-2150. [CrossRef]

31. Tibaoui, T.; Ayachi, S.; Chemek, M.; Alimi, K. New bridged oligofuran for optoelectronic applications. Spectrochim. Acta. Part. AMol. Biomol. Spectrosc. 2015, 142, 25-33. [CrossRef]

32. Xiong, Y.; Wang, M.; Qiao, X.; Li, J.; Li, H. Syntheses and properties of $\pi$-conjugated oligomers containing furan-fused and thiophene-fused aromatic units. Tetrahedron 2015, 71, 852-856. [CrossRef]

33. Walker, B.; Tamayo, A.B.; Dang, X.-D.; Zalar, P.; Seo, J.H.; Garcia, A.; Tantiwiwat, M.; Nguyen, T.-Q. Nanoscale Phase Separation and High Photovoltaic Efficiency in Solution-Processed, Small-Molecule Bulk Heterojunction Solar Cells. Adv. Funct. Mater. 2009, 19, 3063-3069. [CrossRef]

34. Woo, C.H.; Beaujuge, P.M.; Holcombe, T.W.; Lee, O.P.; Fréchet, J.M.J. Incorporation of Furan into Low Band-Gap Polymers for Efficient Solar Cells. J. Am. Chem. Soc. 2010, 132, 15547-15549. [CrossRef] [PubMed]

35. Gidron, O.; Dadvand, A.; Sheynin, Y.; Bendikov, M.; Perepichka, D.F. Towards "green" electronic materials. $\alpha$-Oligofurans as semiconductors. Chem. Commun. 2011, 47, 1976-1978. [CrossRef] [PubMed]

36. Ferron, C.C.; Delgado, M.C.R.; Gidron, O.; Sharma, S.; Sheberla, D.; Sheynin, Y.; Bendikov, M.; Navarrete, J.T.L.; Hernandez, V. $\alpha$-Oligofurans show a sizeable extent of $\pi$-conjugation as probed by Raman spectroscopy. Chem. Commun. 2012, 48, 6732-6734. [CrossRef] [PubMed]

37. Gidron, O.; Varsano, N.; Shimon, L.J.W.; Leitus, G.; Bendikov, M. Study of a bifuran vs. bithiophene unit for the rational design of $\pi$-conjugated systems. What have we learned? Chem. Commun. 2013, 49, 6256-6258. [CrossRef]

38. Gidron, O.; Bendikov, M. $\alpha$-Oligofurans: An Emerging Class of Conjugated Oligomers for Organic Electronics. Angew. Chem. Int. Ed. 2014, 53, 2546-2555. [CrossRef] 
39. Sheberla, D.; Patra, S.; Wijsboom, Y.H.; Sharma, S.; Sheynin, Y.; Haj-Yahia, A.-E.; Barak, A.H.; Gidron, O.; Bendikov, M. Conducting polyfurans by electropolymerization of oligofurans. Chem. Sci. 2015, 6, 360-371. [CrossRef]

40. Huang, J.-D.; Wen, S.-H.; Deng, W.-Q.; Han, K.-L. Simulation of Hole Mobility in $\alpha$-Oligofuran Crystals. J. Phys. Chem. B 2011, 115, 2140-2147. [CrossRef]

41. Steen, A.E.; Ellington, T.L.; Nguyen, S.T.; Balasubramaniam, S.; Chandrasiri, I.; Delcamp, J.H.; Tschumper, G.S.; Hammer, N.I.; Watkins, D.L. Characterization of Furan- and Thiophene-Containing Bispyridyl Oligomers via Spectroscopic, Electrochemical, and TD-DFT Methods. J. Phys. Chem. C 2019, 123, 15176-15185. [CrossRef]

42. Howard, A.A.; Tschumper, G.S.; Hammer, N.I. Effects of hydrogen bonding on vibrational normal modes of pyrimidine. J. Phys. Chem. A 2010, 114, 6803-6810. [CrossRef] [PubMed]

43. Howard, J.C.; Hammer, N.I.; Tschumper, G.S. Structures, energetics and vibrational frequency shifts of hydrated pyrimidine. ChemPhysChem 2011, 12, 3262-3273. [CrossRef] [PubMed]

44. Wright, A.M.; Joe, L.V.; Howard, A.A.; Tschumper, G.S.; Hammer, N.I. Spectroscopic and computational insight into weak noncovalent interactions in crystalline pyrimidine. Chem. Phys. Lett. 2011, 501, 319-323. [CrossRef]

45. Wright, A.M.; Howard, A.A.; Howard, J.C.; Tschumper, G.S.; Hammer, N.I. Charge transfer and blue shifting of vibrational frequencies in a hydrogen bond acceptor. J. Phys. Chem. A 2013, 117, 5435-5446. [CrossRef]

46. Kelly, J.T.; Xu, S.; Graham, J.; Nilles, J.M.; Radisic, D.; Buonaugurio, A.M.; Bowen, K.H.; Hammer, N.I.; Tschumper, G.S. Photoelectron Spectroscopic and Computational Study of Hydrated Pyrimidine Anions. J. Phys. Chem. A 2014, 118, 11901-11907. [CrossRef]

47. DeBlase, A.F.; Wolke, C.; Weddle, G.H.; Archer, K.; Jordan, K.; Kelly, J.T.; Tschumper, G.S.; Hammer, N.I.; Johnson, M.A. Water network-mediated, electron-induced proton transfer in anionic $\left[\mathrm{C}_{5} \mathrm{H}_{5} \mathrm{~N} \cdot\left(\mathrm{H}_{2} \mathrm{O}\right)_{n}\right]^{-}$ clusters. J. Chem. Phys. 2015, 143, 144305. [CrossRef]

48. Kelly, J.T.; McClellan, A.K.; Joe, L.V.; Wright, A.M.; Lloyd, L.T.; Tschumper, G.S.; Hammer, N.I. Competition between Hydrophilic and Argyrophilic Interactions in Surface Enhanced Raman Spectroscopy. ChemPhysChem 2016, 17, 2782-2786. [CrossRef]

49. Wang, Y.; Zhang, X.; Lyapustina, S.; Nilles, M.M.; Xu, S.; Graham, J.D.; Bowen, K.H.; Kelly, J.T.; Tschumper, G.S.; Hammer, N.I. The onset of electron-induced proton-transfer in hydrated azabenzene cluster anions. Phys. Chem. Chem. Phys. 2016, 18, 704-712. [CrossRef]

50. Rahm, M.; Hoffmann, R.; Ashcroft, N.W. Atomic and Ionic Radii of Elements 1-96. Chem. A Eur. J. 2016, 22, 14625-14632. [CrossRef]

51. Hendsbee, A.D.; Sun, J.-P.; McCormick, T.M.; Hill, I.G.; Welch, G.C. Unusual loss of electron mobility upon furan for thiophene substitution in a molecular semiconductor. Org. Electron. 2015, 18, 118-125. [CrossRef]

52. NIST. NIST Standard Reference Database 101: Computational Chemistry Comparison and Benchmark DataBase; Release 20 ed.; National Institute of Standards and Technology (NIST): Gaithersburg, MD, USA, 2019.

53. Lord, R.C.; Marston, A.L.; Miller, F.A. Infra-red and Raman spectra ot the diazines. Spectrochim. Acta 1957, 9 , 113-125. [CrossRef]

54. Verbitskiy, E.V.; Rusinov, G.L.; Charushin, V.N.; Chupakhin, O.N.; Cheprakova, E.M.; Slepukhin, P.A.; Pervova, M.G.; Ezhikova, M.A.; Kodess, M.I. Consecutive SNH and Suzuki-Miyaura Cross-Coupling Reactions-An Efficient Synthetic Strategy to Pyrimidines Bearing Pyrrole and Indole Fragments. Eur. J. Org. Chem. 2012, 2012, 6612-6621.

55. Li, J.-H.; Zhu, Q.-M.; Xie, Y.-X. Pd(OAc) 2 /DABCO-catalyzed Suzuki-Miyaura cross-coupling reaction in DMF. Tetrahedron 2006, 62, 10888-10895. [CrossRef]

56. Boys, S.F.; Bernardi, F. The calculation of small molecular interactions by the differences of separate total energies. Some procedures with reduced errors. Mol. Phys. 1970, 19, 553-566. [CrossRef]

57. Simon, S.; Duran, M.; Dannenberg, J.J. How does basis set superposition error change the potential surfaces for hydrogen-bonded dimers? J. Chem. Phys. 1996, 105, 11024-11031. [CrossRef]

58. Frisch, M.J.; Trucks, G.W.; Schlegel, H.B.; Scuseria, G.E.; Robb, M.A.; Cheeseman, J.R.; Scalmani, G.; Barone, V.; Petersson, G.A.; Nakatsuji, H.; et al. Gaussian 16 Rev. C.01. 2016. Available online: https: //gaussian.com/relnotes/ (accessed on 30 September 2019).

59. Zhao, Y.; Truhlar, D.G. The M06 suite of density functionals for main group thermochemistry, thermochemical kinetics, noncovalent interactions, excited states, and transition elements: Two new functionals and systematic testing of four M06-class functionals and 12 other functionals. Theor. Chem. Acc. 2008, 120, 215-241. 
60. Dunning, T.H. Gaussian basis sets for use in correlated molecular calculations. I. The atoms boron through neon and hydrogen. J. Chem. Phys. 1989, 90, 1007-1023. [CrossRef]

61. Kendall, R.A.; Dunning, T.H.; Harrison, R.J. Electron affinities of the first-row atoms revisited. Systematic basis sets and wave functions. J. Chem. Phys. 1992, 96, 6796-6806. [CrossRef]

62. Woon, D.E.; Dunning, T.H. Gaussian basis sets for use in correlated molecular calculations. III. The atoms aluminum through argon. J. Chem. Phys. 1993, 98, 1358-1371. [CrossRef]

63. Peterson, K.A.; Shepler, B.C.; Figgen, D.; Stoll, H. On the Spectroscopic and Thermochemical Properties of ClO, BrO, IO, and Their Anions. J. Phys. Chem. A 2006, 110, 13877-13883. [CrossRef] [PubMed]

64. Peterson, K.A.; Figgen, D.; Goll, E.; Stoll, H.; Dolg, M. Systematically convergent basis sets with relativistic pseudopotentials. II. Small-core pseudopotentials and correlation consistent basis sets for the post-d group 16-18 elements. J. Chem. Phys. 2003, 119, 11113-11123. [CrossRef]

65. Kozuch, S.; Martin, J.M.L. Halogen Bonds: Benchmarks and Theoretical Analysis. J. Chem. Theory Comput. 2013, 9, 1918-1931. [CrossRef] [PubMed]

66. Dolomanov, O.V.; Bourhis, L.J.; Gildea, R.J.; Howard, J.A.K.; Puschmann, H. OLEX2: A complete structure solution, refinement and analysis program. J. Appl. Crystallogr. 2009, 42, 339-341. [CrossRef]

67. Sheldrick, G. A short history of SHELX. Acta Crystallogr. Sect. A 2008, 64, 112-122. [CrossRef]

(C) 2019 by the authors. Licensee MDPI, Basel, Switzerland. This article is an open access article distributed under the terms and conditions of the Creative Commons Attribution (CC BY) license (http://creativecommons.org/licenses/by/4.0/). 